\title{
Плотность городской ткани и население жилых кварталов
}

\author{
О.С.Глозман, ЦНИИП Минстроя России, Москва \\ И.А.Крашенинников, МАРХИ, Москва
}

Современная градостроительная практика планирования развития транспортных систем городов основывается на математических расчётах транспортных потоков. Когда планируется реконструкция или строительство достаточно крупной транспортной системы, специалисты применяют математическое моделирование транспортных потоков. Важным исходным параметром для моделирования транспортных потоков является количество людей, живущих или работающих на определённой территории. Последнее десятилетие градостроители сталкиваются с проблемой определения численности населения квартала или микрорайона. В настоящей статье описана методика определения численности людей, проживающих в жилых районах, основанная на анализе типа застройки. Данная методика может быть использована в градостроительстве при прогнозировании и моделировании транспортных потоков ${ }^{1}$.

Ключевые слова: градостроительство, транспортные системы, математическое моделирование транспортных потоков, плотность населения, пористость городской ткани.

\section{The Density of the Urban Fabric and the Population of Residential Areas}

O.S.Glozman, TsNIIP Minstroy of Russia, Moscow

I.A.Krasheninnikjv, MARHI, Moscow

The modern town planning practice of planning of the urban transport systems development is based on mathematical calculations of traffic flows. When reconstruction or construction of a sufficiently large transport system is planned, specialists apply mathematical modeling of traffic flows. The number of peopleliving or working in a certain area is important source data for modeling traffic flows. In the last decade urban planners faced the problem of determining the population of a quarter or neighborhood. In this article the method of approximate determination of number of inhabitants is based on an analysis of the type of housing. This technique can be used in urban planning in forecasting and modeling of traffic flows.

\footnotetext{
${ }^{1}$ Данное исследование частично проведено в рамках НИР Минстроя РФ «Формирование базовых стратегических направлений развития транспортной инфраструктуры городов России», выполняемом в ФГБУ «Центральный научно-исследовательский и проектный институт Министерства строительства и жилищно-коммунального хозяйства Российской Федерации» (ФГБУ «ЦНИИП Минстроя России»).
}

Keywords: urban planning, transport systems, mathematical modeling of traffic flows, population density, the porosity of urban fabric.

Планирование развития транспортных систем городов в современном мире невозможно без математического моделирования транспортных потоков. Транспортные потоки моделируют на макро- и микроуровне. В настоящей статье затронуты вопросы, связанные с макромоделированием. Макромодели - модели, применяемые для прогноза корреспонденций и загрузки сети, возникающей в результате развития как самой сети, так и города в целом. Транспортная модель предназначается для прогноза транспортных и пассажирских потоков в городе, включая пешеходное движение. Макромодели применяют для прогнозирования последствий строительства и модернизации транспортной инфраструктуры, строительства и реконструкции микрорайонов жилой застройки и иных объектов. Прежде чем реализовать какие-либо изменения в транспортной инфраструктуре или построить новое здание, специалисты моделируют ситуацию в программном комплексе, что позволяет совершать меньше градостроительных ошибок.

Чем достовернее будут исходные данные для формирования математической модели, тем точнее будет прогноз транспортных и пассажирских потоков.

Исходными данными для моделирования транспортных потоков являются данные о подвижности населении, а также данные о размещении в плане города объектов, порождающих передвижения, то есть мест проживания и приложения труда, объектов торговли и обслуживания населения [1]. Данными о подвижности населения служат определённые на основе статистических наблюдений и социологических опросов значения среднего количества передвижений, совершаемых с различными целями в течение суток средним жителем. Данные об объектах эпизодического посещения (торговли, обслуживания и пр.), как правило, легко найти в открытом доступе. Данные о местах приложения труда обычно собирают по крупицам, изучая каждое здание и каждую организацию, используя все доступные ресурсы.

Наибольшие сложности разработчики математической модели испытывают с определением количества живущих на определённой территории людей. Статистические данные переписи населения охватывают очень большие территории, такие, к примеру, как район Москвы площадью в 500-1000 га, где проживает не менее 50 000-150 000 жителей. 
Такие данные нельзя использовать в математической модели, так как для её корректной работы параметры рассматриваемого района должны быть в 10-20 раз меньше, чем административный район города. Важно отметить, что сейчас усиливается тенденция проживания не по месту регистрации, что также ухудшает достоверность информации.

В последние несколько лет в Москве проводят уточнение математической модели московского региона по данным сотовых операторов [2]. Эта новаторская практика скорее всего не получит распространения на территории России, поскольку для получения данных от операторов сотовой связи нужен серьёзный административный ресурс. Данные операторов сотовой связи очень объёмны, и на их обработку требуются существенные временные и материальные затраты, которые не сможет покрыть ресурс, выделяемый на разработку математической модели транспортных потоков в городах России.

Предлагается алгоритм определения численности населения жилых районов, основанный на дифференциации застройки. Данным алгоритмом можно пользоваться для различных градостроительных задач, например, для определения реальной плотности жилого фонда или расчёта требуемого количества и ёмкости социально значимых объектов. Данный алгоритм существенно упрощает и разработку математической модели транспортной системы города, поскольку для выявления количества проживающих на территории людей достаточно только карты города и определения типа застройки.

Если углубится в историю создания математических моделей транспортных систем городов России, которая начинается с А.М. Якшина и продолжается А.И. Стрельниковым, Б.В.Черепановым и Ю.3 Шершевским и др. [3], то на всём протяжении развития транспортного моделирования специалисты определяли количество живущих на территории людей «экспертно», то есть «на глазок». Необходимо отдать должное вышеперечисленным специалистам и их коллегам и признать, что их экспертное мнение довольно точно определяло требуемые параметры. Однако в современном мире всё подвергается сомнению и требует доказательств. Последние десять-пятнадцать лет не утихают споры по поводу достоверности исходных данных той или иной модели города, и аргументы типа «экспертное мнение профессионала» уже поднимаются на смех. В таких городах как Москва, НижнийНовгород, Екатеринбург, где создана не одна математическая модель, каждый разработчик пытается нейтрализовать конкурента доказывая, что его исходные данные верны, а конкурента - нет.

В сложившихся условиях представленный ниже метод определения численности населения жилых образований сверхактуален для получения объективных исходных данных при разработке математической модели транспортной системы города.

\section{Метод определения численности населения жилых образований}

Для определения численности населения жилых районов предлагается воспользоваться графиком, связывающим четыре показателя городской застройки так, что по двум из них можно вывести третий.

Исследования плотности по теме «Пространство, плотность и форма города» (Space, Dencity and Urban Form.), проведённые в Дельфтском университете, определили вли-

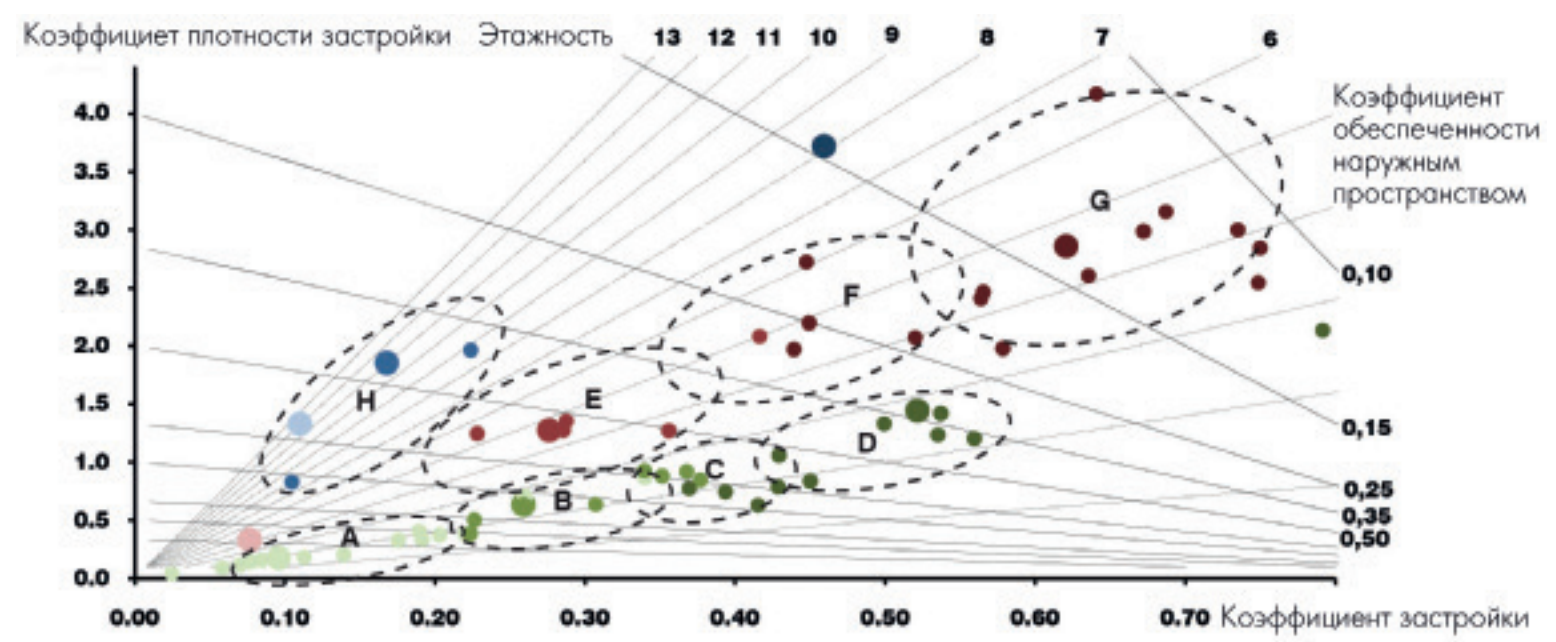
A Низкоэтажная павильонная
E Среднеэтажная строчная
В Низкоэтажная строчная
F Среднеэтажная гибриднаяквартальная/
Сизкоэтажная гибридная строчная/ строчная квартольная
G Среднеэтажная квартальная
D Низкоэтожная көортольная
H Высотная гибридная паеипьонная/строчная

Рис. 1. График зависимости основных показателей, определяющих форму застройки: коэффициент плотности застройки; коэффициент застройки; средняя этажность; коэффициент Обеспеченности наружным пространством 
яние коэффициента плотности застройки, коэффициента застройки и этажности на форму застройки [4]

Результатом многолетней работы стал график, объединяющий данные показатели (рис. 1).

Данные исходного графика были актуализированы в ходе сравнения более сорока примеров современной застройки, выполненного на основе открытых данных. Размер рассматриваемых территорий соответствует современным представлениям о размере планировочной ячейки жилой застройки. Моделирование дало возможность определить ряд натуральных показателей и их соотношения для различных типов застройки. В график включены основные показатели, которые определяют форму застройки:

- коэффициент плотности застройки (коэффициент использования территории);

- коэффициент застройки (коэффициент застроенности территории).

При классических формах застройки из этого графика можно также получить среднюю этажность и коэффициент обеспеченности наружным пространством.

Ниже приведены условные обозначения для натуральных показателей и формулы для определения коэффициентов:

$S_{\text {п }}$ - полезная площадь (суммарная площадь наземной части зданий);

$S_{\text {у }}$ - площадь участка; $S_{3}$ - площадь пятна застройки; $L-$ средняя этажность;

$K_{\text {пз }}$ - коэффициент плотности застройки: $K_{\text {пз }}=S_{\text {п }} / S_{\text {у }}$ (FAR, FSI);

$K_{3}$ - коэффициент застройки: $K_{3}=S_{3} / S_{\mathrm{y}} ; S_{\text {п }}=S_{3} \times L$;

$L=S_{\text {пा }} / S_{3}=\left(S_{\text {п }} / S_{\mathrm{y}}\right) /\left(S_{3} / S_{\text {у }}\right)=K_{\text {пз }} / K_{3^{\prime}} ;$

$S_{\text {нп }}$ - площадь наружных пространств: $S_{\text {нп }}=S_{\mathrm{y}} \times S_{3}$;

$K_{\text {нп }}$ - коэффициент наружных пространств:

$K_{\mathrm{HI}}=S_{\mathrm{y}} \times S_{3} / S_{\mathrm{y}} ; K_{\mathrm{Hп}}=1 K_{3} ;$

$K_{\text {онп }}$ - коэффициент обеспеченности наружным пространством:

$K_{\text {онп }}=S_{\text {нп }} / S_{\text {п }}=\left(S_{\mathrm{y}} \times S_{3} / S_{\mathrm{y}}\right) /\left(S_{\text {п }} / S_{\mathrm{y}}\right)=K_{\text {нп }} / K_{\text {пз }}$.

На графике по оси Х отображены значения коэффициента застройки, а по оси $Y$ - значения коэффициента плотности застройки. На графике значения средней этажности и коэффициента обеспеченности наружным пространством показаны диагональными линиями, делящими график на сектора. Это позволяет быстрее и нагляднее (без выполнения расчёта с помощью приведённых выше формул) определять среднюю этажность и обеспеченность наружным пространством. График позволяет по форме застройки определить коэффициент плотности застройки и, соответственно, плотность населения.

На основе данных о площади застройки и этажности можно определить общую жилую площадь на территории. Важно, что коэффициент плотности застройки, коэффициент застройки, средняя этажность и коэффициент обеспеченности наружным пространством являются взаимозависимыми показателями. Зная два из них, по графику можно опреде- лить остальные. Для определения количества населения необходимо общую площадь квартир поделить на принятую в городе норму жилищной обеспеченности. Следует учесть, что площадь квартир составляет около 70\% от общей площади наземной части жилой застройки. Для подсчёта плотности населения при расчёте необходимо учитывать только жилую часть застройки.

Однако для гибридной застройки сложной формы данный график не работает. Выявлены случаи, когда с помощью графика получаются недостоверные показатели средней этажности для участков застройки со сложной объёмно-пространственной композицией. Например, десятиэтажный урбан-блок с внутренним двором, расположенным на одноэтажном стилобате, даст среднюю этажность, равную пяти. По графику были получены недостоверные коэффициенты обеспеченности наружным пространством для участков с эксплуатируемыми кровлями, стилобатами и террасами. Эксплуатируемые кровли увеличивают площадь наружных пространств и способствуют росту обеспеченности наружным пространством, что не учитывается на графике. Для анализа застройки сложной формы необходимо использовать дополнительный график плотности и «пористости» городской ткани [5].

Данные характеристики и расчёты представлены для участков городской застройки внутри красных линий, что соответствует значениям «нетто» в технико-экономических показателях планировочных ячеек. Исследуемые участки представляют собой кварталы, группы жилой застройки или жилые комплексы.

\section{Расчёт показателей плотности брутто}

Полученные показатели плотности нетто не учитывают пространство улиц, площадей и парков, окружающих кварталы и жилые территории. Для подсчёта показателей плотности в масштабе городской ткани (брутто), нам необходимо учесть площадь, занятую улично-дорожной сетью, парками, площадями, детскими садами, школами, поликлиниками и магазинами. Наружное пространство в городской ткани - это сумма площадей улиц в городской ткани и наружных пространств участков застройки внутри красных линий. Коэффициент плотности городской ткани (брутто) равен отношению полезной площади застройки к площади участка городской ткани.

Необходимо еще раз упомянуть о важности выбора участка для анализа. Показатели плотности будут меняться в зависимости от размера участка. Для одного и того же типа застройки плотность нетто будет больше, чем плотность брутто.

Математическое моделирование транспортных потоков невозможно без понимания количества людей, реально (а не по регистрации) проживающих в каждом конкретном микрорайоне.

Определение численности населения и плотности застройки может быть использовано в градостроительной практике для расчёта транспортных моделей и требуемого количества и ёмкости социально-значимых объектов. 
Описанная методика определения численности населения жилых образований позволяет рассчитать численность проживающих людей, а следовательно и плотность населения не по городу в целом, как это предлагает статистика, а по конкретному микрорайону или даже урбан-блоку.

Применение методики определения численности населения жилых образований повысит достоверность и оперативность получения исходных данных для математического моделирования транспортных потоков.

\section{Лumepamypa}

1. Estimated Atmospheric Emission from Motor Transport in Moscow Based on Transport Model of the City / V. Donchenko Y. Kunin, A. Ruzski [I dr.] // Transportation Research Procedia. - 2016. - № 14.- P. 2649-2658.

2. Бахирев, И.А. Транспортная модель московского региона [Электронный ресурс] / И.А. Бахирев; материалы круглого стола «Моделирование транспортных потоков при разработке документов территориального планирования». 19 апреля 2018 г. // Институт Генплана Москвы. Официальный сайт. - Режим доступа: https://genplanmos.ru/publication/2018_04_19_ krug_stol/ /(дата обращения: 29.05.2018).

3. Стрельников, А.И. Транспортная модель как инструмент проектирования развивающегося объекта - город / А.И. Стрельников // Фундаментальные, поисковые и прикладные исследования РАACH по научному обеспечению развития архитектуры, градостроительства и строительной отрасли РФ. Том 1. - M.: PAACH, 2017. - C. 540-544.

4. Meta Berghauser Pont and Per Haupt. Space, Dencity and Urban Form. - Delft: Delft University of Technology, 2009 $-306 c$.
5. Крашенинников, И.А. Перспективы анализа «пористости» городской ткани [Электронный ресурс] / И.А. Крашенинников // Architecture and Modern Information Technologies. Электронный журнал. - 2017. - № 3 (40). - С. 215-226. - . - Режим доступа: http://marhi.ru/AMIT/2017/3kvart17/16_ krasheninninkov/index.php (дата обращения21.09.2018).

\section{Literatura}

2. Bahirev I.A. Transportnaya model' moskovskogo regiona [Elektronnyj resurs] / I.A. Bahirev; materialy kruglogo stola «Modelirovanie transportnyh potokov pri razrabotke dokumentov territorial'nogo planirovaniya». 19 aprelya $2018 \mathrm{~g}$. // Institut Genplana Moskvy. Oficial'nyj sajt. - Rezhim dostupa: https://genplanmos.ru/publication/2018_04_19_krug_stol/ / (data obrashheniya: 29.05.2018).

3. Strel'nikov A.I. Transportnaya model' kak instrument proektirovaniya razvivayushhegosya ob"ekta - gorod / A.I. Strel'nikov // Fundamental'nye, poiskovye i prikladnye issledovaniya RAASN po nauchnomu obespecheniyu razvitiya arhitektury, gradostroitel'stva i stroitel'noj otrasli RF. Tom1. M.: RAASN, 2017. - S. 540-544.

5. Krasheninnikov I.A. Perspektivy analiza «poristosti» gorodskoj tkani [Elektronnyj resurs] / I.A. Krasheninnikov // Architecture and Modern Information Technologies. Elektronnyj zhurnal. - 2017. - № 3 (40). - S. 215-226. - . - Rezhim dostupa: http://marhi.ru/AMIT/2017/3kvart17/16_krasheninninkov/ index.php (data obrashheniya21.09.2018).

Глозман Ольга Сергеевна (Москва). Кандидат технических наук. Старший научный сотрудник ФГБУ «Центральный научно-исследовательский и проектный институт Министерства строительства и жилищно-коммунального хозяйства» (119331, Москва, просп. Вернадского, 29. ЦНИИП Минстроя России). Сфера научных интересов: подземная урбанистика, транспортные системы городов. Автор 26 научных публикаций. Тел.: +7 (903) 745-79-15. E-mail: 7457915@gmail.com.

Крашенинников Иван Алексеевич, 1992 г.р. (Москва). Аспирант ФГБОУ В0 «Московский архитектурный институт» (государствекнная академия) Московского Архитектурного института (Государственная академия) (107031, Москва, ул. Рождественка, 11/4. МАРХИ). Сфера научных интересов: плотность и «пористость» городской ткани, обеспеченность наружным пространством в застройке. Автор 8 научных публикаций. Тел.: +7 (916) 074-60-48. E-mail: Dekrash@mail.ru.

Glozman Olga Sergeevna (Moscow). Candidate of Technical Sciences. Senior Researcher of the FGBU "The Central Institute for Research and Design of the Ministry of Construction and Housing and Communal Services of the Russian Federation" (119331, Moscow, Vernadskogo ave., 29. TsNIIP Minstroy of Russia). Research interests: underground urbanistics, transport systems of cities. The author of 26 scientific publications. Tel.: +7 (903) 745-79-15. Email: 7457915@gmail.com.

Krasheninnikov Ivan Alekseevich, born in 1992 (Moscow). Postgraduate student of the Moscow State Architectural Institute (State Academy) (107031, Moscow, Rozhdestvenka St, 11/4. MArchI). Research interests: density and "porosity" of urban fabric, provision of outdoor space in buildings. The author of 8 scientific publications. Tel.: +7 (916) 074-60-48. E-mail: Dekrash@mail.ru. 